\title{
Comparative study of surgical results between total abdominal hysterectomy and total laparoscopic hysterectomy in a tertiary hospital: a 2 year retrospective study
}

\author{
Kanmani M.*, Mirudhubashini Govindarajan, Vishranthi Selvaraj
}

Department of Obstetrics and Gynecology, Women's Center hospitals, Coimbatore, Tamil Nadu, India

Received: 30 December 2017

Accepted: 31 January 2018

*Correspondence:

Dr. Kanmani M.,

E-mail: drmkdpi@gmail.com

Copyright: (c) the author(s), publisher and licensee Medip Academy. This is an open-access article distributed under the terms of the Creative Commons Attribution Non-Commercial License, which permits unrestricted non-commercial use, distribution, and reproduction in any medium, provided the original work is properly cited.

\begin{abstract}
Background: Since the introduction of Laparoscopic hysterectomy by Reich in 1989, it has become a widely accepted technique worldwide. The aim of the study was to compare the surgical results between Total Laparoscopic Hysterectomy (TLH) and Total Abdominal Hysterectomy (TAH).

Methods: We conducted a retrospective study at Women's center and hospitals between June 2014 to May 2016, 32 patients who underwent TAH and 55 patients who underwent TLH, were included.

Results: We observed that there was no significant difference between the two groups in respect to patient's demographic characteristics, indication of surgery, uterine size, or with history of previous pelvic surgery. Duration of surgery was found to be longer in TLH than TAH (124 $\pm 39.7 \mathrm{~min}$ vs. $104.7 \pm 39.8 \mathrm{~min})$. The length of hospital stay was less in TLH than TLH (P-0.0001) and the amount of blood loss were also less in TLH than TAH (103 \pm 149 ml versus $243 \pm 210 \mathrm{ml}$ ). There was no significant difference in view of intra and post operative complications. Hemoglobin change was statistically significant and is more with TAH than TLH $(1.57 \pm 0.7 \mathrm{~g} \%$ versus $1.12 \pm 0.7 \mathrm{~g} \%)$.

Conclusions: This study showed that TLH can be safely performed by the experienced surgeon in order to reduce the blood loss, duration of hospital stay and the quality of life.
\end{abstract}

Keywords: Fetal distress, Hypertension in pregnancy, Stillbirths

\section{INTRODUCTION}

Since the introduction of Laparoscopic hysterectomy by Reich in 1989, it has become a widely accepted technique worldwide. Laparoscopic hysterectomy was reported to have lower post op morbidity, improved quality of life, less hospital stay, less blood loss when compared to Laparotomy. ${ }^{1,2}$ The intention of a laparoscopy is to convert an abdominal hysterectomy to a minimally invasive laparoscopic/vaginal hysterectomy. Laparotomy is still a preferable technique by most of the surgeons, may be due to lack of extensive training of surgeon and the team. Laparoscopic approach may not be feasible in patients with history of multiple abdominal surgery, dense pelvic/ bowel adhesions and large fibroids and in morbid obesity where Laparotomy takes the lead.

The aim of this study was to compare the intra and post operative results of TAH (Total Abdominal Hysterectomy) and TLH (Total Laparoscopic Hysterectomy).

\section{METHODS}

A Retrospective non randomised study was carried out in Womens center hospital, Coimbatore, Tamilnadu, India, 
comparing TLH and TAH. The study period was from June 2014 to May 2016 (24 months). We reviewed the medical records and theatre register of 87 patients; factors examined include demographic details, indication for operation, intra-operative details, histopathology summary, post-operative recovery and subsequent postoperative review findings.

Number of patients included in this study was 87, they were classified into two groups of which 55 patients underwent TAH and 32 underwent TLH. Patients with malignancies were excluded.

In this study, the distribution of patient characteristics and indications of hysterectomy is listed in Table 1. Intra and post operative results were listed in Table 2. All patients had pathologically confirmed benign lesions.

\section{Operative techniques}

Both the TAH and TLH were performed by the gynecologists. Patients were generally admitted one day prior to surgery for bowel preparation.Prophylactic antibiotic Cefazolin $1 \mathrm{gm}$ was given preoperatively 30minutes before surgery. Supine position was used for TAH, where as Trendelenburg position was used for TLH. In TAH - After induction of anesthesia and the patient in supine position, a midline vertical abdominal incision was made to proceed to hysterectomy.

TLH - The procedure was performed same as LAVH above the uterine artery level. After laparoscopic dissection of the bladder flap and resection of the broad ligament, the uterine artery was coagulated by bipolar coagulation and was separated from the uterine sidewall by harmonic. Then bilateral coagulation and transection of the cardinal-uterosacral ligament complex were performed carefully.

The cervicovaginal junction was confirmed with vaginal tube through the vagina. Circular colpotomy was then performed close to the cervix. The uterus was removed through the vagina and sent for histological examination. Endosutures were placed on the vaginal cuff.

The duration of operation was calculated from the first skin incision for the Veress needle insertion to the last suture of the abdominal wound. Blood loss was calculated from aspiration and pad soakage. Postoperative medication was administered intravenously for analgesia and cefazolin intravenously, for prophylaxis for the first $24 \mathrm{hr}$.

Febrile morbidity was defined as an oral temperature of $100.4^{\circ} \mathrm{F} / 38.0^{\circ} \mathrm{C}$ or higher, excluding the first $24 \mathrm{~h}$ postoperatively. Duration of hospital stay was calculated from the day of surgery to the day of discharge. Patients were discharged when they were afebrile, with normal voiding, and off analgesic.

\section{Statistical analysis}

Data were presented as mean and SD or percentage. A statistical analysis of the data was performed using unpaired Student's t test, Mann-Whitney U, Fisher exact test for parametric or non-parametric variables and the chi-square test, where appropriate, for categorical variables. Pearson correlation coefficient was done to find significance between operative time and blood loss. $\mathrm{P}<0.05$ was considered statistically significant.

\section{RESULTS}

The distribution of baseline characteristics of the patients was showed in Table 1 . The mean age (46.5 \pm 8.9 vs. $46.9 \pm 6.9, \mathrm{P}-0.8)$ and the mean BMI $(27.7 \pm 5.6$ vs. $26 \pm 4.7$ $\mathrm{kg} / \mathrm{m}^{2}, \mathrm{P}-0.13$ ) for the TAH and TLH groups respectively were comparable. We were able to do the planned surgical procedure in both modalities. In one case, conversion of TLH to Laparotomy was done due to dense bowel adhesions to the posterior surface of the uterus. There was no significant difference noted between the two groups regarding parity, cesarean delivery, previous pelvic surgery or the indication of surgery.

Table 1: Distribution of patient characteristics and Indication of surgery.

\begin{tabular}{|c|c|c|c|}
\hline & $\begin{array}{l}\text { TAH } \\
(n=32)\end{array}$ & $\begin{array}{l}\text { TLH } \\
(\mathrm{n}=55)\end{array}$ & $\begin{array}{l}\mathbf{P} \\
\text { value }\end{array}$ \\
\hline Age years & $46.5 \pm 8.9$ & $46.9 \pm 6.9$ & $0.8^{\mathrm{a}}$ \\
\hline BMI & $27.7 \pm 5.6$ & $26 \pm 4.7$ & $0.13^{\mathrm{a}}$ \\
\hline Parity & $1.59 \pm 1.2$ & $1.56 \pm 0.7$ & $0.9^{\mathrm{a}}$ \\
\hline Caesarean delivery & $0.72 \pm 0.9$ & $0.55 \pm 0.8$ & $0.36^{\mathrm{a}}$ \\
\hline \multicolumn{4}{|c|}{ Previous pelvic surgery } \\
\hline Sterilisation & 4 & 12 & \\
\hline Myomectomy & 3 & 2 & \\
\hline Adnexectomy & 2 & 0 & \\
\hline Total & $9(28)$ & $14(25.4)$ & $0.78^{b}$ \\
\hline \multicolumn{4}{|c|}{ Indication of surgery } \\
\hline Fibroid & $16(50)$ & $37(67)$ & $\mathrm{NS}^{\mathrm{b}}$ \\
\hline Adenomyosis & $8(25)$ & $12(21)$ & $\mathrm{NS}^{\mathrm{b}}$ \\
\hline Endometriosis & $4(12.5)$ & $3(5.5)$ & $\mathrm{NS}^{\mathrm{b}}$ \\
\hline Ovarian cyst & $3(9.4)$ & $1(1.8)$ & $\mathrm{NS}^{\mathrm{b}}$ \\
\hline DUB & $1(3.1)$ & $2(3.7)$ & $\mathrm{NS}^{\mathrm{b}}$ \\
\hline
\end{tabular}

TLH-Total Laparoscopic Hysterectomy, TAH-Total Abdominal Hysterectomy. Values are given as mean \pm SD or $\mathrm{n}(\%)$. aStudent's t test, ${ }^{\text {bChi-square test }}$

The intra operative and post-operative results were showed in Table 2. In TLH group, the operative time was significantly longer than in TAH group (124 \pm 39.7 vs. $104 \pm 39.8 \mathrm{~min}, \mathrm{P}-0.03)$. There were no significant differences between the two groups regarding complications like organ injury, vault hematoma, fever or repeat surgery.

Blood loss $(243 \pm 210 \mathrm{ml}$ versus $163 \pm 149 \mathrm{ml}, \mathrm{P}-0.02)$ and the haemoglobin change $(1.57 \pm 0.7$ versus $1.12 \pm 0.7 \mathrm{~g} \%)$ were significant between TAH and TLH groups. 
Table 2: Intra and post operative results.

\begin{tabular}{|llll|}
\hline $\begin{array}{l}\text { TAH } \\
(\mathbf{n = 3 2})\end{array}$ & $\begin{array}{l}\text { TLH } \\
(\mathrm{n}=55)\end{array}$ & $\begin{array}{l}\text { P } \\
\text { value }\end{array}$ \\
\hline $\begin{array}{l}\text { Duration of } \\
\text { surgery, min }\end{array}$ & $104.7 \pm 39.8$ & $124 \pm 39.7$ & $0.03^{\mathrm{a}}$ \\
\hline $\begin{array}{l}\text { Blood losses, ml } \\
\text { Hospital stay, days }\end{array}$ & $243 \pm 210$ & $163 \pm 149$ & $0.02^{\mathrm{b}}$ \\
\hline Uterine size, cm & $13.36 \pm 5.4$ & $11.16 \pm 2.9$ & $0.18^{\mathrm{b}}$ \\
\hline $\begin{array}{l}\text { Complications } \\
\text { Hemoglobin } \\
\text { change, g\% }\end{array}$ & $1.57 \pm 0.7$ & $1.12 \pm 0.7$ & $0.005^{\mathrm{a}}$ \\
\hline Vault hematoma & 2 & $1(1.8)$ & $\mathrm{NS}^{\mathrm{c}}$ \\
\hline $\begin{array}{l}\text { Fever } \\
\text { Bowel injury }\end{array}$ & 0 & $2(3.6)$ & $\mathrm{NS}^{\mathrm{c}}$ \\
\hline Bladder injury & 0 & $1(1.8)$ & $\mathrm{NS}^{\mathrm{c}}$ \\
\hline Ureteric injury & 0 & $1(1.8)$ & $\mathrm{NS}^{\mathrm{c}}$ \\
\hline Wound infection & 9 & $1(1.8)$ & $\mathrm{NS}^{\mathrm{c}}$ \\
\hline $\begin{array}{l}\text { Conversion to } \\
\text { laparotomy }\end{array}$ & 0 & 0 & $<0.0001$ \\
\hline Repeat surgery & 1 & $1(1.8)$ & $\mathrm{NS}^{\mathrm{c}}$ \\
\hline
\end{tabular}

TLH-Total Laparoscopic Hysterectomy, TAH-Total Abdominal Hysterectomy. Values are given as mean \pm SD or n $(\%)$. NS=Not significant. 'Students's t test; 'Mann-Whitney U test; 'Fisher's exact test.

The amount of blood loss shown in Figure 1. There was no correlation between the duration of surgery and the blood loss in both TAH and TLH (P- 0.061 and P- 0.74). Duration of hospital stay was extremely significant (6.5 \pm 2.2 vs. $4.63 \pm 1.2$ days, $\mathrm{P}-0.0001)$ between the TAH and TLH groups.

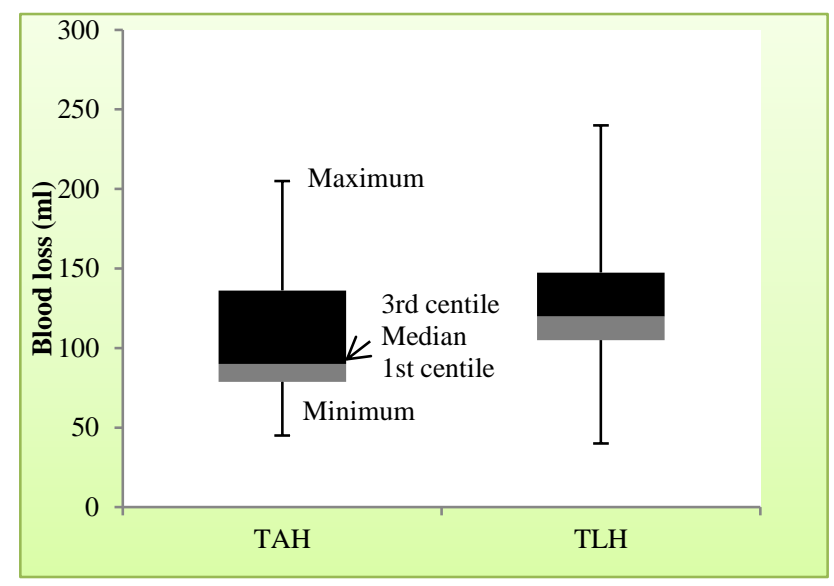

Figure 1: Total amount of blood loss in TAH and TLH.

\section{DISCUSSION}

The present retrospective study compares the intra and post operative outcomes between TLH and TAH. Hence, in our centre initially we introduced LAVH as minimally invasive procedure.

From June 2014 we have started doing TLH after training. It has been widely reported that Laparoscopic hysterectomy was associated with less operative time, less blood loss and shorter hospital stay. Here we have discussed the previous reported outcomes with present study.

A comparative study performed by Doganay et al, on peri operative morbidity in abdominal, vaginal and total laparoscopic hysterectomy concluded that abdominal and vaginal hysterectomy necessitated significantly more reoperation than $\operatorname{TLH}\left(0.4,0.2,0.0 \%\right.$, respectively). ${ }^{3}$

Jahan et al, conducted a prospective study on the outcome of LAVH, TAH, Vaginal hysterectomy on 750 patients. ${ }^{4}$ They concluded that LAVH and vaginal hysterectomy were associated with reduced blood loss, less complication rates, less post operative pain and shorter hospital stay.

A systematic review by Kluivers et al, observed that laparoscopic hysterectomy performs equally or better in terms of postoperative health and quality of life in the first weeks after surgery. ${ }^{1}$ In the decision for an approach to hysterectomy, the advantage of better quality of life should be offset against the increased risk of complications in laparoscopic hysterectomy.

A meta-analysis of TAH versus TLH for benign disease by Colin et al, reported that the laparoscopic approach may offer advantages over TAH with respect to minor peri-operative complications, blood loss and hospital stay but the only trade off appears to be longer operating time. They also addressed that larger studies are needed to analyze uncommon but major complications like vessel injury, organ injury and long term morbidity such as pelvic organ prolapsed and sexual and bladder dysfunction. $^{2}$

In most of the studies compared the clinical outcomes between total laparoscopic hysterectomy and abdominal hysterectomy and reported to have shorter hospitalization, reduced blood loss and longer operative time in TLH. Their complication rates were insignificant between the two groups but the skin wound infection rates in our study were extremely significant in TAH than TLH $(\mathrm{P}<0.0001) .^{5-7}$

In present study, we also had reduced blood loss and reduced duration of surgery in TLH when compared to TAH. But there was no significance between the operating time and the amount of blood loss.

A study by Nanavati et al, showed reduced blood loss in TLH and they had shorter hospital stay when compared with TAH although the operating time is high in TLH. ${ }^{8}$

Virupaksha et al reported that there were no significant complications between TLH and TAH but TLH took longer operating time. They also observed that TLH required less post operative analgesia than TAH. ${ }^{9}$ 
In present study, there was no significance in the categorizing the patients depending on the uterine size, for the mode of surgery. We encountered 3 major complications in TLH of which one patient had bowel injury in which, the patient had dense bowel adhesions to anterior abdominal wall, one patient had bladder injury which was noted intra operatively and repaired.

The other one patient had ureteric injury which was diagnosed in post operative period. The patient had loin pain and fever with increased total counts and ureteric injury was confirmed by imaging and the same managed by urologist.

However, the complications rates in regard to organ injury in TLH which is $5.5 \%(\mathrm{P}-0.29)$ were not significant and are comparable with rates reported in the literature. ${ }^{4,5}$ Three patients needed repeat surgery in TLH, one of those had vault hematoma diagnosed in post operative period and the same needed surgical evacuation of clots. The other 2 patients needed repeat surgery for ureteric repair and for bowel resection and anastamosis. In $\mathrm{TAH}$, one patient underwent repeat surgery for vault hematoma evacuation.

One patient with TLH has been converted to Laparotomy due to dense bowel adhesions to posterior surface of uterus. Vault hematoma occurred in two patients with TAH and one patient in TLH. Laparoscopic hysterectomy needs technical expertise, confidence and experience of the surgeon and proper selection of patient for the success of surgery.

The surgeon should know the limit of skill and be able to decide when to convert to laparotomy in the best interest of the patient. Of course, the surgeon learns from her own or the peer experience and refine the skills day by day. Hence with experience one should be able to do more of TLH than TAH with negligible complications to lower the morbidity. Although laparoscopic hysterectomy depends on the interest of surgeon, it is well said that the mode of hysterectomy should be based on the patients benefit rather than the surgeon's comfort.

Low complication rate can be achieved by extensive training in laparoscopy and optimizing of the technique. Less experienced gynecologic surgeons may experience higher complications when attempting TLH.

The implementation of level three laparoscopic procedures is the high preoperative costs and the long learning curve. However, despite the fact that peri operative costs are higher for laparoscopy due to expensive disposables, it might be that the overall costs will be well balanced between both procedures by the reduction of morbidity and shorter hospital stay.

There were no significant differences between the two groups regarding complications. In the current study, we observed significantly longer operative time in TLH compared with TAH group. It also showed significantly shorter hospitalization with laparoscopy compared with laparotomy. We found a mean duration of hospital stay after TLH of 3 days compared with 6 days after TAH.

However, it is needless to mention that TAH cannot be totally replaced by TLH. Patients with dense adhesions, multiple laparotomies, co morbidities like ventral hernia, where you need to avoid morcellation, not fit for GA, and where time and abdominal distention are a constraint.

\section{CONCLUSION}

Laparoscopic hysterectomy is an emerging alternative to abdominal and difficult non descent vaginal hysterectomy. Though operating time in TLH is longer, it is more beneficial than the traditional TAH for decreasing the length of postoperative hospital stays and intra operative blood loss with no difference in operative complications. However, for patients with more complex pathology, the choice between Laparoscopic hysterectomy and TAH will depend on the surgeon's experience.

\section{Funding: No funding sources}

Conflict of interest: None declared

Ethical approval: The study was approved by the Institutional Ethics Committee

\section{REFERENCES}

1. Kluivers KB, Johnson NP, Chien P, Vierhout ME, Bongers M, Mol BW. Comparison of laparoscopic and abdominal hysterectomy in terms of quality of life: a systematic review. Eur J Obstet Gynecol Reprod Biol. 2008;136(1):3-8.

2. Walsh CA, Walsh SR, Tang TY, Slack M. Total abdominal hysterectomy versus total laparoscopic hysterectomy for benign disease: a meta-analysis. Eur J Obstet Gynecol Reprod Biol. 2009;144(1):3-7.

3. Doganay M, Yildiz Y, Tonguc E, Var T, Karayalcin R, Eryilmaz OG et al. Abdominal, vaginal and total laparoscopic hysterectomy: perioperative morbidity. Arch Gynecol Obstet. 2011;284(2):385-9

4. Jahan S, Das TR, Mahmud N, Mondol SK, Habib SH, Saha S. A comparative study among laparoscopically assisted vaginal hysterectomy, vaginal hysterectomy and abdominal hysterectomy: experience in a tertiary care hospital in Bangladesh. $\mathbf{J}$ Obstet Gynecol. 2011;31(3):254-7.

5. Celik C, Abali R, Tasdemir N, Aksu E, Çalışkan H, Akkuş D. Total laparoscopic hysterectomy compared with abdominal hysterectomy; clinical outcomes. J Clin Anal Med. 2014;5(6):490-3.

6. Cho HY, Choi KJ, Lee YL, Chang KH, Kim HB, Park SH. Comparison of two bipolar systems in laparoscopic hysterectomy. JSLS. 2012;16:456- 60.

7. Kongwattanakul K, Khampitak K. Comparison of laparoscopically assisted vaginal hysterectomy and 
abdominal hysterectomy: a randomized controlled trial. J Min Inv Gynecol. 2012;19(1):89-94.

8. Nanavati AM, Gokral SB. A prospective randomized comparative study of vaginal, abdominal, and laparoscopic hysterectomies. J Obstet Gynaecol India. 2016 Oct 1;66(1):389-94.

9. Ajjammanavar V, Jayashree S, Amrutha B. Total laparoscopic hysterectomy versus total abdominal hysterectomy: a retrospective study. J Evid Based Med Healthcare. 2015;2(41):7019-25.

Cite this article as: Kanmani M, Govindarajan M, Selvaraj V. Comparative study of surgical results between total abdominal hysterectomy and total laparoscopic hysterectomy in a tertiary hospital: a 2 year retrospective study. Int J Reprod Contracept Obstet Gynecol 2018;7:1019-23. 